\title{
Decline of depressive symptoms in Europe: differential trends across the lifespan
}

\author{
Johannes Beller ${ }^{1}$ (1) Enrique Regidor ${ }^{2,3} \cdot$ Lourdes Lostao $^{4} \cdot$ Alexander Miething $^{5} \cdot$ Christoph Kröger $^{6}$. \\ Batoul Safieddine ${ }^{1} \cdot$ Fabian Tetzlaff $^{1} \cdot$ Stefanie Sperlich $^{1} \cdot$ Siegfried Geyer $^{1}$
}

Received: 4 March 2020 / Accepted: 24 October 2020 / Published online: 12 November 2020

(c) The Author(s) 2020

\begin{abstract}
Purpose We examined changes in the burden of depressive symptoms between 2006 and 2014 in 18 European countries across different age groups.

Methods We used population-based data drawn from the European Social Survey ( $N=64.683,54 \%$ female, age $14-90$ years) covering 18 countries (Austria, Belgium, Denmark, Estonia, Finland, France, Germany, Great Britain, Hungary, Ireland, The Netherlands, Norway, Poland, Portugal, Slovenia, Spain, Sweden, Switzerland) from 2006 to 2014. Depressive symptoms were measured via the CES-D 8. Generalized additive models, multilevel regression, and linear regression analyses were conducted.

Results We found a general decline in CES-D 8 scale scores in 2014 as compared with 2006, with only few exceptions in some countries. This decline was most strongly pronounced in older adults, less strongly in middle-aged adults, and least in young adults. Including education, health and income partially explained the decline in older but not younger or middleaged adults.

Conclusions Burden of depressive symptoms decreased in most European countries between 2006 and 2014. However, the decline in depressive symptoms differed across age groups and was most strongly pronounced in older adults and least in younger adults. Future studies should investigate the mechanisms that contribute to these overall and differential changes over time in depressive symptoms.
\end{abstract}

Keywords Depression $\cdot$ Mental health $\cdot$ Trend $\cdot$ Population $\cdot$ Compression of morbidity

Johannes Beller

Beller.Johannes@mh-hannover.de

1 Medical Sociology Unit, Hannover Medical School, Center for Public Health and Health Care, Carl-Neuberg-Street 1, 30625 Hannover, Germany

2 Department of Public Health and Maternal and Child Health, Complutense University of Madrid, Madrid, Spain

3 CIBER Epidemiología y Salud Pública (CIBERESP), Madrid, Spain

4 Department of Medical Sociology, Public University of Navarre, Pamplona, Spain

5 Department of Public Health Sciences, Stockholm University, Stockholm, Sweden

6 Department of Clinical Psychology and Psychotherapy, Institute of Psychology, University of Hildesheim, Hildesheim, Germany

\section{Introduction}

Depression is one of the most common and severe mental impairments. It is estimated that about 264 million people worldwide are affected [32]. Besides being a serious disorder itself, depression is also a major predictor of other healthrelated outcomes like cardiovascular events, treatment noncompliance, musculoskeletal pain, absenteeism, dementia, and suicide [16, 20, 21, 45]. Accordingly, the Global Burden of Disease Study of the World Health Organization estimates that depression is one of the leading causes of disability $[34,54]$.

The general term depression encompasses a spectrum, ranging from single depressive symptoms, through subthreshold forms of depressive disorder, to severe recurrent major depressive disorder [2, 35]. It is increasingly recognized that even single symptoms of depression are of great public health importance, because even in the absence of a major 
depressive disorder, they could be associated with significant morbidity. For example, chronic feelings of loneliness have been described as being equally important to risk factors such as obesity and smoking [30], and have been found to predict mortality as well as impaired physical, functional, cognitive and mental health $[5,8,9,19]$. Thus, due to its high prevalence and its far-reaching individual and societal consequences, depression is of major public health importance.

Therefore, there is a need to study cross-temporal differences in depressive symptoms. Several studies have analysed trends in depression, mostly focusing on specific age-groups. For example, Keyes et al. [36] recently analysed trends in depression of students of the 8th, 10th, and 12th grade from 1991 to 2018. Depression was measured as a continuous construct via self-report as a sum score of four depressive symptoms. The authors found that depressive symptoms increased among teens in the United States over time, especially among girls. Similarly, another study analysed cross-temporal differences of a sum-score of self-reported depressive symptoms in Icelandic adolescents and also found increasing levels of depression in girls [52]. In a similar age range, Mojtabai et al. [48] analysed trends in the prevalence of depression using a short structured interview among youth aged 12-25. They found an increase, especially among adolescents. Zivin et al. [59] analysed trends of depression among older adults in the US. Using prevalence estimates based on the eight-item Center for Epidemiologic Studies Depression Scale (CES-D 8), they found that depressive symptoms decreased over time in US older adults. Similarly, Sullivan et al. [51] used a modified version of the CES-D 8, analysed a continuous depressive symptom burden score as well as a dichotomous cut-off and found that depressive burden of older adults decreased across birth cohorts. Hence, evidence on trends in depression mostly originates from the US and focuses on specific age groups.

Only few studies used the whole age range, including youth, young adults, middle-aged adults and older adults, and examined whether there were significantly differential trends across the lifespan (i.e., for people of different ages, from young to older adults). In one of these studies, Weinberger et al. [56] examined trends in the depression prevalence in the US. The authors found that depression prevalence significantly increased across time, but that this increase significantly differed between age groups, with depression in the youngest increasing the most strongly. In another study, Bretschneider et al. [15] examined trends in the depression prevalence in Germany. In their study, the depression prevalence was found to be relatively constant overall. However, the authors also found a shift in the age distribution in women, with significant increases in the depression prevalence among the young age group (age 18-34), no significant change in the middle-aged age group (age 35-49) and a significant decrease in the old age group (age 50-65). All studies point towards the need to further study cross-temporal differences in depression, considering the whole lifespan and using multi-national samples.

From a theoretical point of view, several theories have been developed to describe the general morbidity development at the population level. Among them, Fries [22] suggested that over time serious morbidity will occur ever later in the life course, such that there is a compression of morbidity towards the end of life. Contradicting this position, Gruenberg [27] and Kramer [39] suggested that there will be increasing morbidity, especially concerning mental disorders and physical chronic conditions. Whereas numerous studies have focused on physical conditions such as functional limitations, evidence regarding mental disorders is missing $[11,23]$.

The current study aims to address these issues. It contributes to the literature by examining changes in depressive symptoms between 2006 and 2014 in several European countries (Austria, Belgium, Denmark, Estonia, Finland, France, Germany, Great Britain, Hungary, Ireland, The Netherlands, Norway, Poland, Portugal, Slovenia, Spain, Sweden, Switzerland) by covering the age groups from youth to old age (age range: $14-90 ; N=64,683$ ). Thereby the current study clarifies:

(a) whether the depressive symptom burden has changed in Europe between 2006 and 2014;

(b) whether the burden of depressive symptoms differ across age groups (14-90 years);

(c) whether these potential changes in depressive symptoms can be generalized across countries in Europe; and

(d) how these potential differences might be explained.

\section{Materials and methods}

\section{Sample}

Data were drawn from the public release of the cumulative European Social Survey (ESS) that aims to provide comparative data on attitudes, beliefs and behaviour patterns of the various populations in Europe. The ESS also includes rotating modules, which are dedicated to specific themes that are sometimes repeated in later survey rounds. We used data from the eighteen countries (Austria, Belgium, Denmark, Estonia, Finland, France, Germany, Great Britain, Hungary, Ireland, The Netherlands, Norway, Poland, Portugal, Slovenia, Spain, Sweden, Switzerland) that participated in the 2006 and 2014 waves of the ESS, which included rotating modules relating to personal well-being and health. To date, only the 2006 and 2014 waves incorporated measures of depressive symptoms, and as such only these two waves could be included in the current study. The ESS provides population-based crosssectional samples of non-institutionalized participants aged 
14 years and older with the interviews conducted face-to-face at the respondent's place of residence. Thus, at both time points, population-based cross-sectional samples of first-time responders were obtained. Response rates were between 46 and $73 \%$ in 2006 per country (Austria: 65\%, Belgium: 61\%, Denmark: 51\%, Estonia: 65\%, Finland: 64\%, France: $46 \%$, Germany: 55\%, Great Britain: 55\%, Hungary: 66\%, Ireland: 57\%, The Netherlands: $60 \%$, Norway: $66 \%$, Poland: $70 \%$, Portugal: $73 \%$, Slovenia: $65 \%$, Spain: $66 \%$, Sweden: $66 \%$, Switzerland: $52 \%$ ) and between 31 and $68 \%$ in 2014 per country (Austria: 52\%, Belgium: 57\%, Denmark: 52\%, Estonia: 60\%, Finland: 63\%, France: 51\%, Germany: 31\%, Great Britain: 44\%, Hungary: 53\%, Ireland: 61\%, The Netherlands: 59\%, Norway: $54 \%$, Poland: $66 \%$, Portugal: $43 \%$, Slovenia: $53 \%$, Spain: $68 \%$, Sweden: $50 \%$, Switzerland: $53 \%$ ). All procedures were in accordance with the ethical standards of the institutional research committee and with the 1964 Helsinki declaration and its later amendments. After excluding participants with missing values listwise (about $4.3 \%$ of the sample), a final sample with $N=64,683$ participants resulted $\left(N_{2006}=32,578 ; N_{2014}=32,105\right)$.

\section{Measures}

Depressive symptoms were measured with the 8-item version of the Centre of Epidemiologic Studies Depression Scale (CES-D 8) in both 2006 and 2014. Multiple studies have demonstrated the scale's validity and reliability to measure depressive symptoms in different cultures and throughout the lifespan (e.g., $[33,37,38,55])$. The CES-D 8 measures the frequency of depressive symptoms in the week prior to the interview. Participants were asked whether they (1) "felt depressed", (2) "felt lonely", (3) "felt sad", (4, reverse scored) "were happy", (5, reverse scored) "enjoyed life", (6) "felt everything was an effort", (7) "had restless sleep", and (8) "could not get going". Participants could choose to respond with one of four response options ranging from "none or almost none of the time" (score 0 ) to "all or almost all of the time" (score 3). In accordance with psychometric evidence, a dimensional total depressive symptoms score was calculated as the sum of all responses ranging from 0 to 24 [41]. Additionally, it was investigated whether the results are robust to the analysis of a dichotomous depression score via cut-off of larger than 9 . In the current study, reliability of the CES-D 8 sum score was acceptable (2006: Cronbach's $\alpha=0.83,2014$ : Cronbach's $\alpha=0.82$ ). In addition to CES-D 8, age, sex, education (measured via the years of full-time education completed) and income and health were assessed. Income was measured via inquiring whether the participants had serious difficulties to cope with the present household income [score $=1$ ], whether they had difficulties coping with the current household income [score $=2$ ], whether they could cope with the present household income [score $=3$ ], or whether they could live comfortably with their household income [score $=4]$.
Finally, current health status was operationalized by asking about participant's self-rated health with answer options ranging from "very bad" [score =1], "bad" [score=2], "fair" [score $=3$ ] and "good" [score $=4]$ to "very good" [score $=5$ ].

\section{Data analysis}

First, descriptive statistics of all variables across and within countries and the two time periods are reported in the results section. Then bivariate generalized additive model regression analyses were conducted to graphically examine how the CES-D 8 score changes across age. Generalized additive model regressions might be favourably used in the current study, because they are able to depict highly non-linear relationships between variables by fitting several non-linear regression models to multiple localized subsets of the data. Then, to model the average change in depressive symptoms over countries, multilevel regression analyses were applied, controlling for age only. In addition, to estimate how much of the average change in depressive symptoms can be explained by our covariates, we included our full set of covariates (age, sex, education and income) as quantitative covariates in additional multilevel regressions. All participant characteristics were included on level 1 . Country was used as the level 2 grouping factor to account for cross-national differences in depression via varying intercepts. To examine age-specific changes between groups, these multilevel regression analyses were also stratified in three age groups (young adults: 14-39; middle-aged adults: 40-64; older adults: $65+$ ), as has been similarly done in the literature [15]. Differences in regression coefficients between age-groups were examined by $z$-test [17]. Additionally, to better explain these changes in depressive symptom burden over time, education, income and health were included as covariates in further multilevel regression analyses. Finally, to examine the change in depressive symptoms specific for each country, age-stratified linear regression analyses within countries using the country-specific data were conducted. All inferential statistical methods used the design weights provided by the European Social Survey. All statistical analyses were performed with R.

\section{Results}

Overall, participants were on average 47.46 (standard deviation $[\mathrm{SD}]=18.29)$ years old in 2006 and $49.26(\mathrm{SD}=18.48)$ years old in 2014, with 54\% being female in 2006 and 52\% in 2014. Participants had on average $12.29(\mathrm{SD}=4.25)$ years of education in 2006 and $12.96(\mathrm{SD}=4.06)$ years of education in 2014. In 2006 and 2014, participants reported that they could cope with their current income (2006: mean $[M]=3.12$, $\mathrm{SD}=0.80 ; 2014: M=3.12, \mathrm{SD}=0.81$, on a scale of $1-4)$ and that they had good health $(2006: M=3.81, \mathrm{SD}=0.90 ; 2014$ : 
$M=3.82, \mathrm{SD}=0.90$, on a scale of $1-5)$. On average, the sum score of depressive symptoms declined in 2014 (2006: $M=5.72, \mathrm{SD}=4.10 ; 2014: M=5.19, \mathrm{SD}=3.98)$.

Next, we examined differential cross-temporal changes in depressive symptom burden across the lifespan using non-linear generalized additive models. As can be seen in Fig. 1, although depressive symptoms tended to increase with increasing age, a highly non-linear association between both variables emerged. Depressive symptoms appeared to decrease from 2006 to 2014 for the whole age range. The decline in the sum score for depressive symptoms appeared to be strongest in older adults. These effects were in general replicated with single depressive symptoms, although it appears that declines were smaller or even partly reversed into increases in the case of younger adults regarding fatigue, loneliness, and sleep problems Appendix Fig. 3. The results are also replicated when using the proposed cut-off (sum score $>9$ ) to denote a depression prevalence Appendix Fig. 4.

These descriptive differences of decreasing depressive symptoms were confirmed by the age-stratified multilevel regression analyses as depicted in Table 1. Depressive symptoms decreased significantly in women and men and for all age-groups, but the decline was most pronounced in older adults. Pairwise $z$ tests indicated that this decline was indeed significantly strongest in older adults as compared to young- and middle-aged adults both in women and men (all $p$ values $<0.05$ ). As seen in Table 1 , when including the covariates the decline in depressive symptoms was not substantially reduced in younger and middle-aged adults. However, after controlling for education, health and income, the decline was substantially reduced in older men $(-0.813$ vs. -0.676$)$, and women $(-0.840$ vs. -0.489$)$.

Finally, we examined the generalizability of the results by investigating changes in depressive symptom burden within countries, as visualized in Fig. 2 and described in Appendix Tables 2 and 3. Strongest decreases in depressive symptoms were generally observed in Hungary, Poland and Slovenia, whereas the smallest decreases, and among younger adults partly even increases, in depressive symptoms were generally observed in Spain, Norway and Denmark. However, the country-specific results were similar to the overall results reported in the previous paragraph. Except for Spain and, in the case of women, Denmark and Norway, younger and middle-aged adults' depressive symptoms tended to decline. And, except for Ireland, older adults' depressive symptoms also declined but to a greater extent. These general changes were replicated when analysing a specific youth age group (age 14-24, Appendix Fig. 5), although it appears that the country-specific increases in depressive symptoms tended to be stronger in this age bracket. Thus, the country-specific

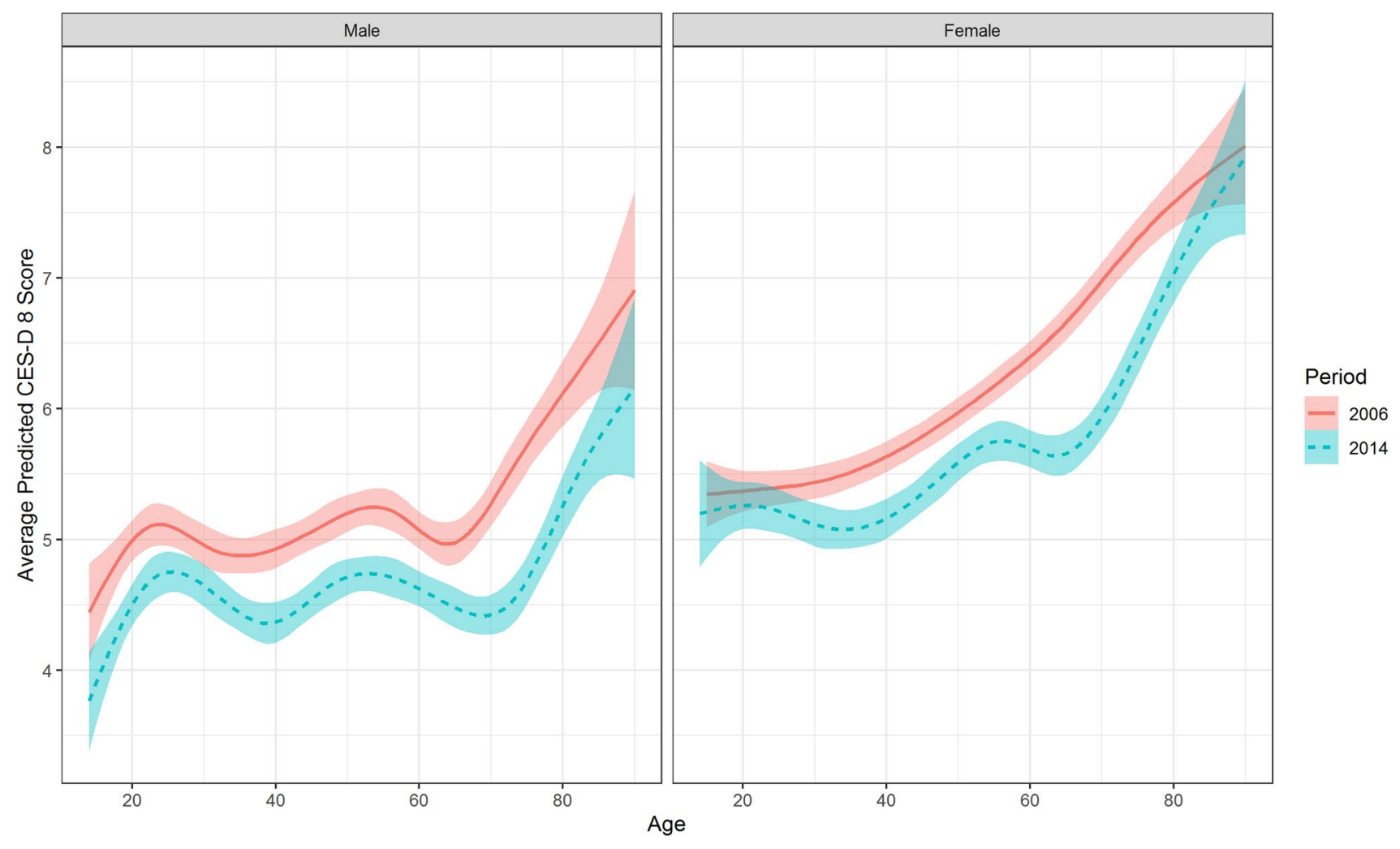

Fig. 1 Average CES-D 8 scores across age between 2006 and 2014 predicted via generalized additive models (shaded areas represent 95\% confidence intervals) 


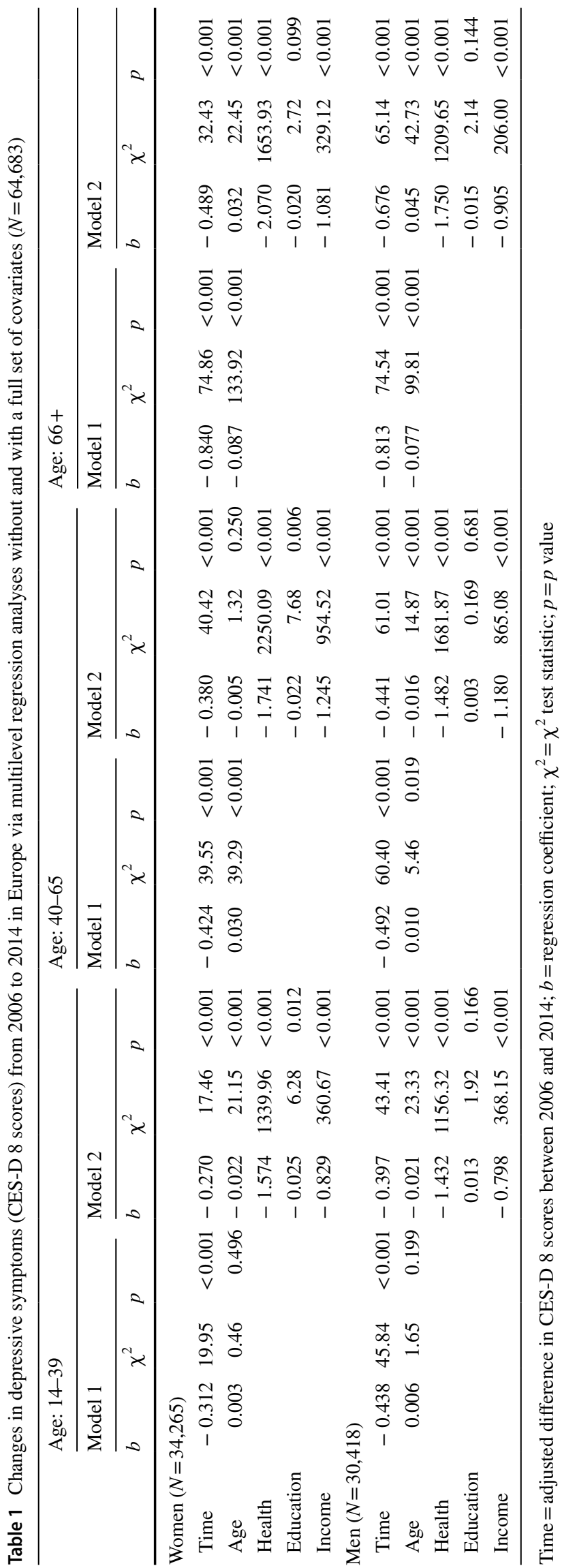

results supported the overall multilevel analyses in that depressive symptoms decreased most strongly in older adults.

\section{Discussion}

We examined cross-temporal changes in depressive symptoms between 2006 and 2014 for multiple countries and different age groups. We found that there was a general decline in depression across time for all age-groups. The strength of this decline differed across the age range: consistent across both sexes and for all countries analysed, we found that depressive symptoms declined most in older adults and less strongly in younger and middle-aged adults.

Our results both contradict and confirm previous studies. Numerous studies had suggested that depression increased in younger adults (e.g., [36, 48, 52]). We found this not to be the case in general. Although young adults' depression scores increased in some countries, in the majority of countries depressive symptoms actually decreased. Contrarily to these trends, some studies had suggested that depression decreased in older adults (e.g., [51, 29]). Supporting these studies, we also found that depression scores decreased strongly for older adults in most countries. Directly comparing these effects in different age groups, we found that there were indeed significantly differential cross-temporal changes in depression across the lifespan, with older adults improving the most. Thus, going beyond the previous literature, the current study suggests (a) that the pattern of cross-temporal changes in depression differs across age, (b) that these changes can be generalized across European countries for older and middleaged but not for younger adults and (c) that the decreases in middle-aged and older adults' depression symptoms burden might largely be explained by predictors relating to general health and socio-economic status, but that these predictors cannot explain the observed results in young adults.

However, several limitations have to be taken into account when interpreting our results. The sample did not include institutionalized older adults and thus likely underestimates the true level of depression in the population. Additionally, we only compared two time points, instead of several. Changes in the level of depression might also be partly explained by changing response rates between time points. It might be the case that potential participants with high depressive symptom burden have become less likely to participate in research. If this was true, then the observed differences would not only be due to changes in the population level of depressive symptom burden but also due to changes in participation rates between time points. Thus, selective participation and systematic dropout are important topics that need to be analysed in future studies. Similarly, although we analysed population-based data of multiple countries, these were only European countries and other continents 

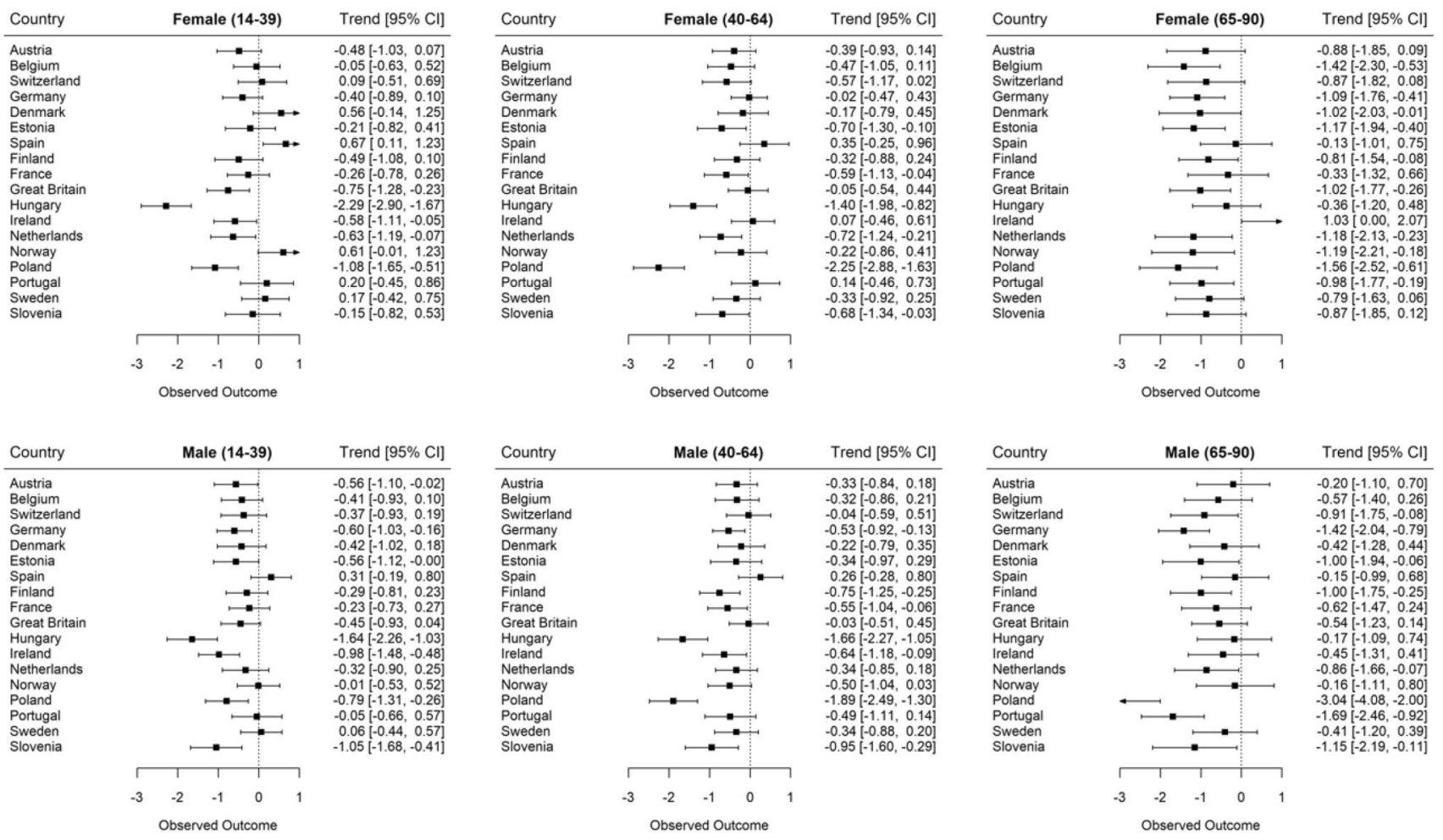

Fig. 2 Changes in depressive symptoms (adjusted mean CES-D 8 score differences with 95\% confidence intervals) between 2006 and 2014 across age-groups and within countries controlled for age

were not represented [28], and levels of depressive symptom burden and changes in depressive symptom burden might differ in other countries. Of course, as the current study still strongly suggests that cross-temporal changes and geographical variations in depressive symptom burden exist, more research on this topic is needed.

We also analysed only a self-report measure of depression, the CES-D 8. As self-reported measures might also be susceptible to biases [44], future studies should investigate differential cross-temporal changes for different age-groups using more objective indicators of depression, like interview-based symptom scores. In a similar vein some of our covariates to explain depression differences, such as income and education, might be sub-optimal indicators in youth and younger adults as compared to middle-aged and older adults. Thus, future studies should try to examine additional predictors of crosstemporal changes in depressive symptom burden.

It also remains to be investigated why cross-temporal changes in some countries diverged from the general results. Contrarily to general trends, Spanish younger and middleaged adults seemed to exhibit increasing depression scores. Some studies have shown an increase in poor mental health, using the Goldberg 12-item scale questionnaire, between 2006 and 2011 in men under 65, but not in women [4, 53]. This finding has been attributed to the impact of the economic crisis, since the increase was greater in unemployed men $[4,53]$. Similarly, although not as statistically significant, young adults' depression scores in the Nordic countries seemed to decrease less than in other countries or even increased. Several studies speculated about rising socioeconomic inequalities and perceived stress as possible explanation for this phenomenon [1, 57]. For example, in the Swedish context it has been found that major changes in the school system were accompanied by lower school achievements and lower employment rates, which then might explain the less favorable developments in mental health among younger adults from Nordic countries like Sweden [14]. Finally, in contrast to older adults from other countries, older female adults in Ireland were found to also significantly increase in depression scores. This seems especially concerning as studies have found high rates of depression in women in Ireland, in general [43] - however, empirical evidence that might explain this finding is lacking. For example, crossnational variations in depressive symptom burden might also be partly due to differing response rates. However, contrarily to this preposition, most countries showed declines in depressive symptom burden irrespective of the respective changes in response rates. Similarly, increases in depressive symptom burden partly occurred in Denmark, Spain and Sweden, although response rates changed differentially between these countries. Still, future studies are needed that provide empirical explanations for the observed differences across 
countries. Finally, some studies have pointed to the existence of different symptom profiles across the lifespan [47]. Future studies might examine whether, in addition to additive changes in the symptom severity, there are also changes in depression profiles across the life span over time.

The result that older adults have benefitted the most is important from a demographic perspective. Increases in life expectancy and decreases in fertility are leading to an ever increasing share of older adults in the general population [12]. As such, the finding that morbidity in the form of depressive symptoms in older adults decreased strongest opposes Greenberg's expansion of morbidity hypothesis, which states that over time old age will be increasingly associated with higher levels of morbidity [27]. At the same time, these results support Fries' morbidity compression hypothesis that morbidity at the end of life can be managed and appears to be reducing [22].

The finding that younger adults' depression scores decreased the least and even appeared to be increasing in some countries and regarding some depressive symptoms is alarming from a public health perspective. Depressive symptoms are seen as relatively stable throughout the life course $[42,49]$. As such, if some of today's young adults start off with more depressive symptoms than previous generations, then they are also likely to experience significantly more depressive symptoms as they age. This would not only impede their physical, mental and cognitive health, but it would also necessitate a greater burden on health care systems as well. Thus, more research is needed to clarify whether younger age cohorts actually increasingly experience depressive symptoms, for example using age-periodcohort analysis [5-7, 58]. Additionally, special prevention efforts should be targeted at younger adults. However, to effectively improve health of these groups, knowledge about the reasons for their health impediment is indispensable.

There are several possible explanations for these crosstemporal changes. Medical and societal advances might have improved treatment availability and treatment effectiveness: Studies have found that help-seeking behaviour for depressive symptoms and the effectiveness of treatments for depressive symptoms has increased over time [13, 29, 40]. This might also explain the increasing frequency of depression diagnoses [31, 50]. As more people with depressive symptoms seek help, the observed administrative prevalence of depression increases and the depressive symptom burden in the population decreases. As such people might be treated earlier and more effectively for depressive symptoms over time [18].

Additionally, we examined some potential predictors of depressive symptom burden changes in the current study. It was found that the inclusion of education, income and health substantially decreased the decline in older adults. This suggests that a combination of the expansion of education, the decrease in poverty, and the improvement of general health have likely contributed to the substantial decrease of depressive symptoms in older adults $[23,46]$. At the same time, including these covariates could not substantially explain declines in young and middle-aged adults. Thus, further research must examine age-specific risk factors for depression that might explain these differential effects, such as problematic social media use, or changes in other lifestyle factors [3, $25,26]$. Another methodological explanation is that cognitive biases might have unduly influenced self-reports. Perhaps, in accordance with an anchor effect, the self-perceived threshold of what it means to experience depressive symptoms has increased over time in older adults, such that the reporting but not the level of depression has decreased [24]. Lastly, however, future studies must empirically analyse the origin of these changes and why they appear especially strong in older adults but are less pronounced in younger age cohorts.

Summing up, we investigated time differences in depressive symptoms in multiple European countries and analysed whether these cross-temporal changes differed across age. Using population-based data of Europeans from 18 countries, we found that there was a general decline in depressive symptoms. However, time differences in depression differed significantly across the lifespan: with few exceptions, depressive symptoms declined most strongly in older adults and least in younger adults. Future studies should investigate the mechanisms that contribute to these overall and differential trends across the lifespan.

Acknowledgements This paper was funded by the DFG (German Research Foundation), reference number GE 1167/15-1. We gratefully acknowledge the European Social Survey for providing us with the data used in the current study.

Funding Open Access funding enabled and organized by Projekt DEAL.

\section{Compliance with ethical standards}

Conflict of interest There are no conflicts of interest to disclose.

Open Access This article is licensed under a Creative Commons Attribution 4.0 International License, which permits use, sharing, adaptation, distribution and reproduction in any medium or format, as long as you give appropriate credit to the original author(s) and the source, provide a link to the Creative Commons licence, and indicate if changes were made. The images or other third party material in this article are included in the article's Creative Commons licence, unless indicated otherwise in a credit line to the material. If material is not included in the article's Creative Commons licence and your intended use is not permitted by statutory regulation or exceeds the permitted use, you will need to obtain permission directly from the copyright holder. To view a copy of this licence, visit http://creativecommons.org/licenses/by/4.0/.

\section{Appendix}

See Tables 2 and 3, Figs. 3, 4, and 5. 


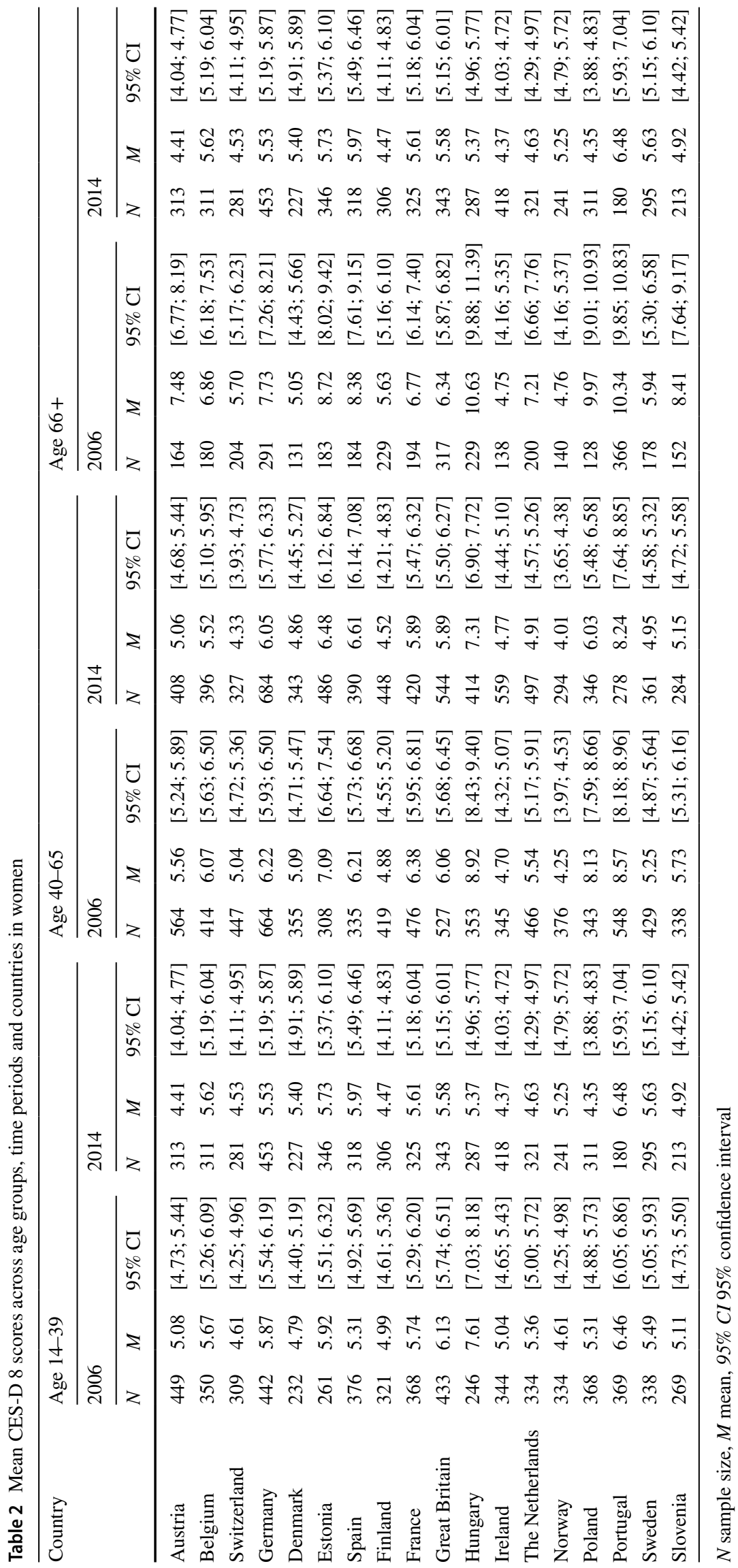




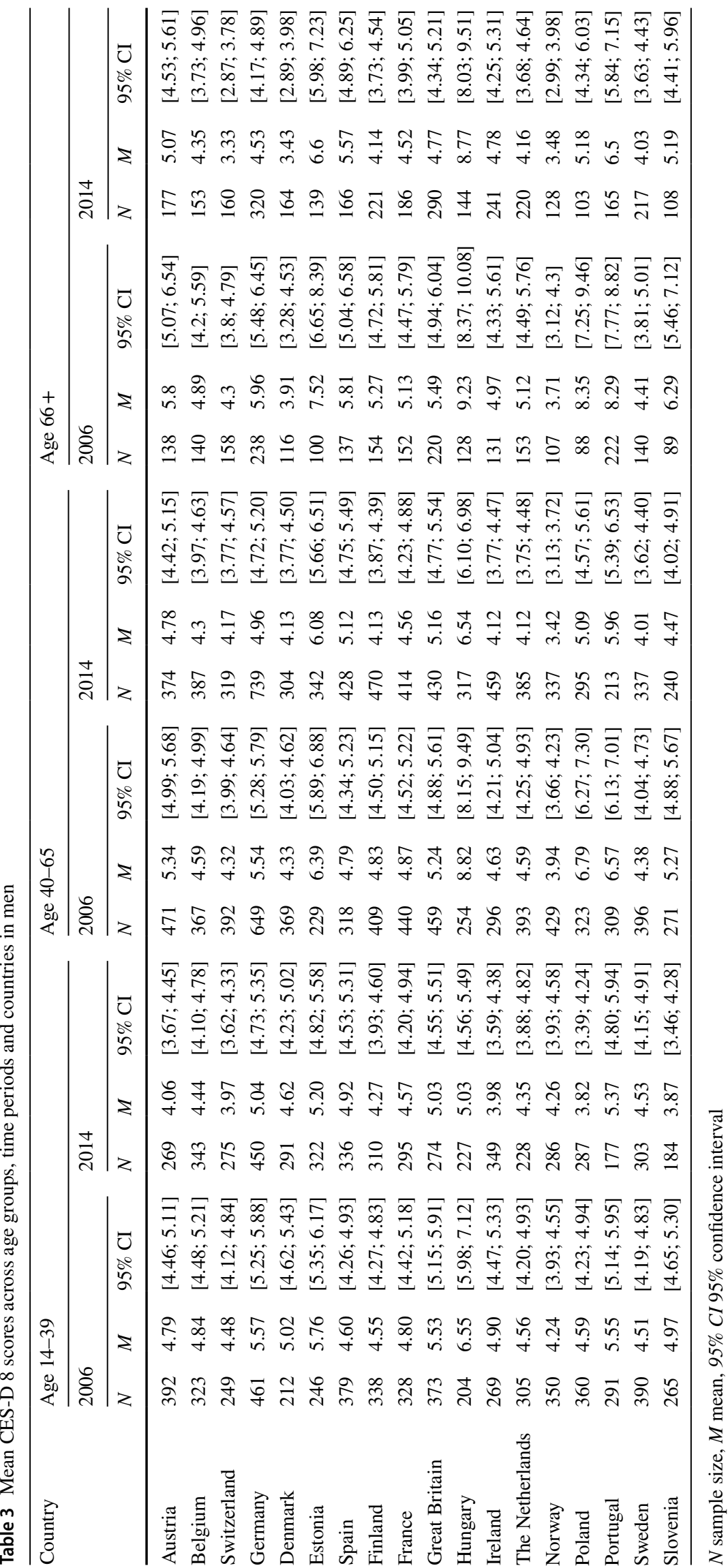


Fig. 3 Average depressive symptom item scores (CES-D 8 items; range: $0-3$ ) across age between 2006 (solid line) and 2014 (dashed line) predicted via generalized additive models (shaded areas represent 95\% confidence intervals)
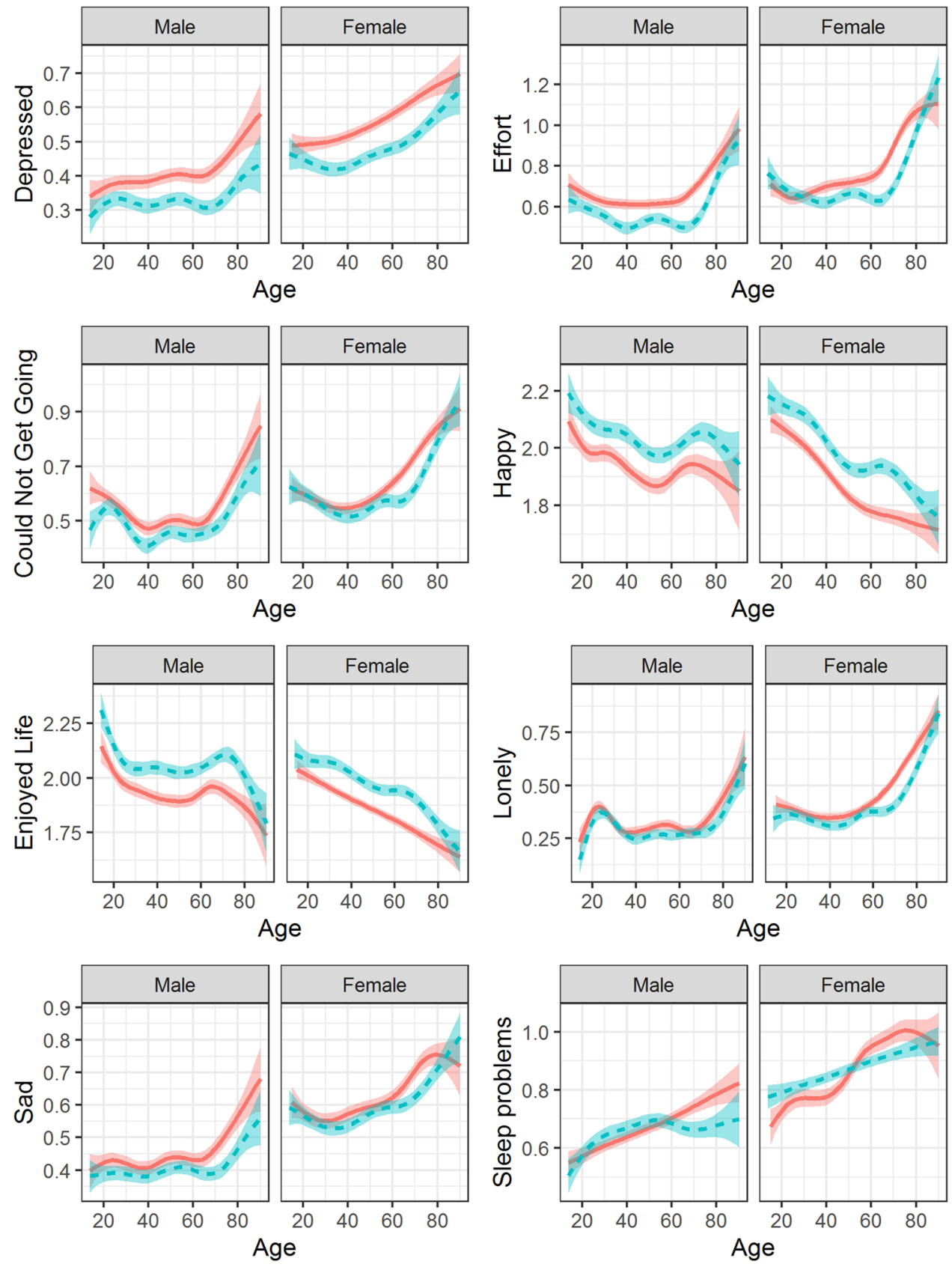


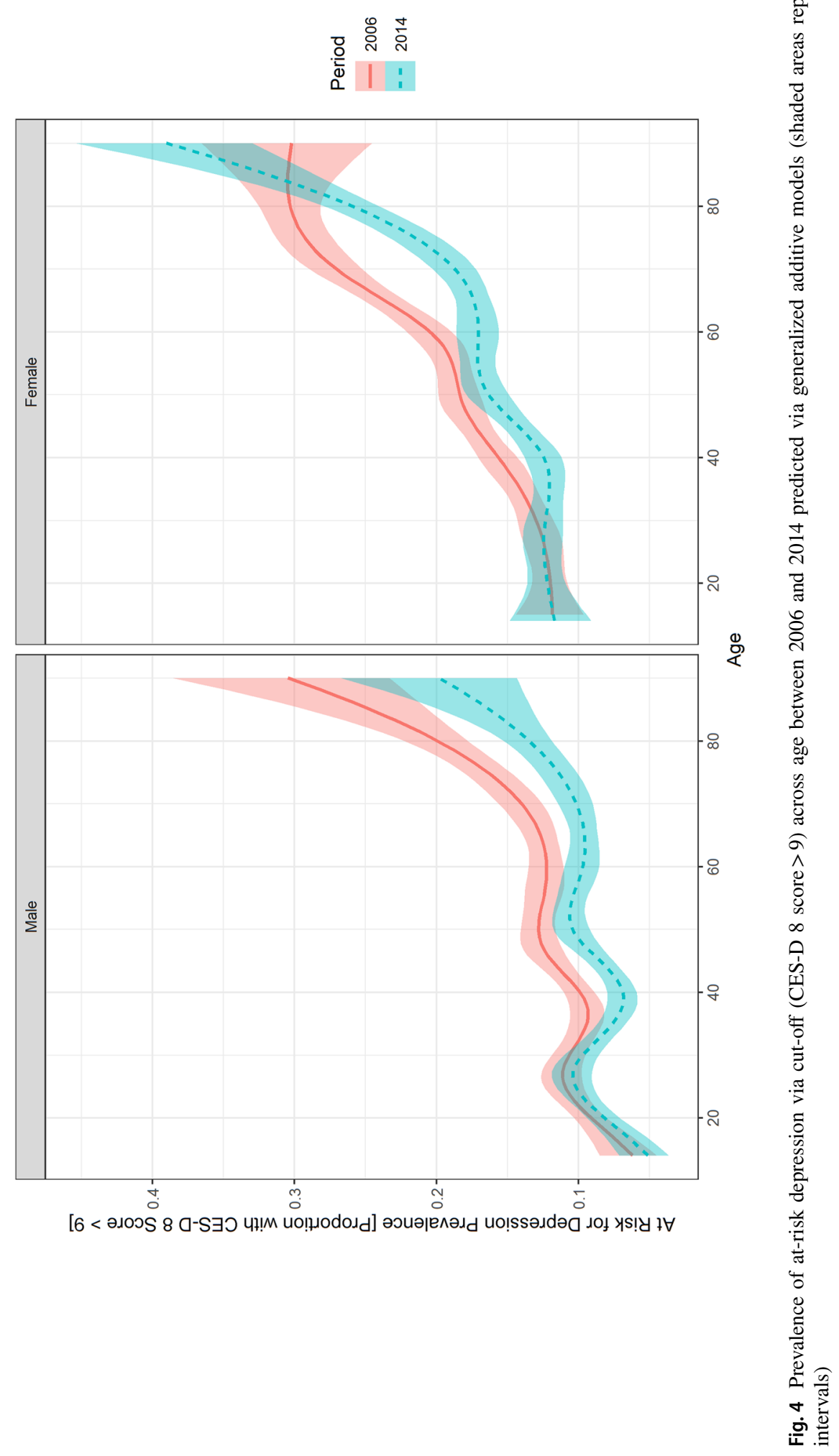




\begin{tabular}{lll} 
Country & Trend [95\% Cl] \\
\hline Austria & Selgium \\
Switzerland \\
Germany \\
Denmark \\
Estonia \\
Spain \\
Finland \\
France \\
Great Britain \\
Hungary \\
Ireland \\
Netherlands \\
Norway \\
Poland \\
Portugal \\
Sweden \\
Slovenia
\end{tabular}

\begin{tabular}{lll} 
Country & Trend $[95 \% \mathrm{Cl}]$ \\
\hline Austria & Belgium \\
Switzerland \\
Germany \\
Denmark \\
Estonia \\
Spain \\
Finland \\
France \\
Great Britain \\
Hungary \\
Ireland \\
Netherlands \\
Norway \\
Poland \\
Portugal \\
Sweden \\
Slovenia
\end{tabular}

\begin{tabular}{lll} 
Country & Trend [95\% Cl] \\
\hline Austria & \\
Belgium \\
Switzerland \\
Germany \\
Denmark \\
Estonia \\
Spain \\
Finland \\
France \\
Great Britain \\
Hungary \\
Ireland \\
Netherlands \\
Norway \\
Poland \\
Portugal \\
Sweden \\
Slovenia
\end{tabular}

\begin{tabular}{lll} 
Country & Trend $[95 \% \mathrm{Cl}]$ \\
\hline Austria \\
Belgium \\
Switzerland \\
Germany \\
Denmark \\
Estonia \\
Spain \\
Finland \\
France \\
Great Britain \\
Hungary \\
Ireland \\
Netherlands \\
Norway \\
Poland \\
Portugal \\
Sweden \\
Slovenia
\end{tabular}

Fig. 5 Changes in depressive symptoms (adjusted mean CES-D 8 score differences with $95 \%$ confidence intervals) from 2006 to 2014 in youth (age 14-24) and young adults (age 25-39) within countries adjusted for age

\section{References}

1. Andersen I, Thielen K, Bech P, Nygaard E, Diderichsen F (2011) Increasing prevalence of depression from 2000 to 2006. Scand J Pub Health 39(8):857-863. https://doi.org/10.1177/1403494811 424611

2. Baldwin G, Shean GD (2006) A taxometric study of the center for epidemiological studies depression scale. Genet Soc Gen Psychol Monogr 132(2):101-128. https://doi.org/10.3200/ MONO.132.2.101-128

3. Bányai F, Zsila Á, Király O, Maraz A, Elekes Z, Griffiths MD, Andreassen CS, Demetrovics Z (2017) Problematic social media use: results from a large-scale nationally representative adolescent sample. PLoS ONE 12(1):e0169839. https://doi.org/10.1371/journ al.pone.0169839

4. Bartoll X, Palència L, Malmusi D, Suhrcke M, Borrell C (2014) The evolution of mental health in Spain during the economic crisis. Eur J Pub Health 24(3):415-418. https://doi.org/10.1093/ eurpub/ckt208

5. Beller $\mathbf{J}$ (2020) Xenophobia trends in Germany: Increasing negative attitude towards foreigners in younger birth cohorts. Soc Sci J 1-7. https://doi.org/10.1080/03623319.2020.1735855

6. Beller J, Epping J (2020) Disability trends in Europe by age-period-cohort analysis: increasing disability in younger cohorts. Disabil Health J 100948. https://doi.org/10.1016/j. dhjo.2020.100948
7. Beller J, Miething A, Regidor E, Lostao L, Epping J, Geyer S (2019) Trends in grip strength: age, period, and cohort effects on grip strength in older adults from Germany, Sweden, and Spain. SSM Popul Health 9:100456. https://doi.org/10.1016/j.ssmph .2019.100456

8. Beller J, Wagner A (2018a) Disentangling loneliness: differential effects of subjective loneliness, network quality, network size, and living alone on physical, mental, and cognitive health. J Aging Health 30(4):521-539. https://doi.org/10.1177/089826431668584 3

9. Beller J, Wagner A (2018b) Loneliness, social isolation, their synergistic interaction, and mortality. Health Psychol 37(9):808-813. https://doi.org/10.1037/hea0000605

10. Beller J, Wagner A (2020) Loneliness and health: the moderating effect of cross-cultural individualism/collectivism. J Aging Health. 089826432094333. https://doi.org/10.1177/0898264320 943336

11. Beltrán-Sánchez H, Razak F, Subramanian SV (2014) Going beyond the disability-based morbidity definition in the compression of morbidity framework. Global Health Action 7(1):24766. https://doi.org/10.3402/gha.v7.24766

12. Bongaarts J (2009) Human population growth and the demographic transition. Philos Trans R Soc B Biol Sci 364(1532):29852990. https://doi.org/10.1098/rstb.2009.0137

13. Brandstetter S, Dodoo-Schittko F, Speerforck S, Apfelbacher C, Grabe H-J, Jacobi F, Hapke U, Schomerus G, Baumeister SE (2017) Trends in non-help-seeking for mental disorders in 
Germany between 1997-1999 and 2009-2012: a repeated crosssectional study. Soc Psychiatry Psychiatr Epidemiol 52(8):10051013. https://doi.org/10.1007/s00127-017-1384-y

14. Bremberg S (2015) Mental health problems are rising more in Swedish adolescents than in other Nordic countries and The Netherlands. Acta Paediatr 104(10):997-1004. https://doi.org/10.1111/ apa. 13075

15. Bretschneider J, Janitza S, Jacobi F, Thom J, Hapke U, Kurth T, Maske UE (2018) Time trends in depression prevalence and health-related correlates: results from population-based surveys in Germany 1997-1999 vs. 2009-2012. BMC Psychiatry 18(1):394. https://doi.org/10.1186/s12888-018-1973-7

16. Briley M, Lépine JP (2011) The increasing burden of depression. Neuropsychiatr Dis Treat 7:3-7. https://doi.org/10.2147/ NDT.S19617

17. Clogg CC, Petkova E, Haritou A (1995) Statistical methods for comparing regression coefficients between models. Am J Sociol 100(5):1261-1293. https://doi.org/10.1086/230638

18. Connolly Gibbons MB, Rothbard A, Farris KD, Wiltsey Stirman S, Thompson SM, Scott K, Heintz LE, Gallop R, CritsChristoph P (2011) Changes in psychotherapy utilization among consumers of services for major depressive disorder in the community mental health system. Admin Pol Mental Health Serv Res 38(6):495-503. https://doi.org/10.1007/s10488-011-0336-1

19. Cuijpers P, Vogelzangs N, Twisk J, Kleiboer A, Li J, Penninx BW (2013) Differential mortality rates in major and subthreshold depression: meta-analysis of studies that measured both. Br J Psychiatry 202(1):22-27. https://doi.org/10.1192/bjp. bp.112.112169

20. DiMatteo MR, Lepper HS, Croghan TW (2000) Depression is a risk factor for noncompliance with medical treatment: metaanalysis of the effects of anxiety and depression on patient adherence. Arch Intern Med 160(14):2101. https://doi.org/10.1001/ archinte.160.14.2101

21. Ferrari AJ, Charlson FJ, Norman RE, Patten SB, Freedman G, Murray CJL, Vos T, Whiteford HA (2013) Burden of depressive disorders by country, sex, age, and year: findings from the global burden of disease study 2010. PLoS Med 10(11):e1001547. https ://doi.org/10.1371/journal.pmed.1001547

22. Fries JF (1980) Aging, natural death, and the compression of morbidity. N Engl J Med 303(3):130-135. https://doi.org/10.1056/ NEJM198007173030304

23. Fries JF, Bruce B, Chakravarty E (2011) Compression of morbidity 1980-2011: a focused review of paradigms and progress. J Aging Res 2011:1-10. https://doi.org/10.4061/2011/261702

24. Furnham A, Boo HC (2011) A literature review of the anchoring effect. J Socio-Econ 40(1):35-42. https://doi.org/10.1016/j.socec .2010.10.008

25. Gehlich KH, Beller J, Lange-Asschenfeldt B, Köcher W, Meinke MC, Lademann J (2019) Consumption of fruits and vegetables: improved physical health, mental health, physical functioning and cognitive health in older adults from 11 European countries. Aging Mental Health 1-8. https://doi.org/10.1080/13607 863.2019.1571011

26. Gehlich KH, Beller J, Lange-Asschenfeldt B, Köcher W, Meinke MC, Lademann J (2019) Fruit and vegetable consumption is associated with improved mental and cognitive health in older adults from non-Western developing countries. Public Health Nutr 22(4):689-696. https://doi.org/10.1017/S1368980018002525

27. Gruenberg EM (1977) The failures of success. Milbank Meml Fund Quart Health Soc 55(1):3. https://doi.org/10.2307/3349592

28. Henrich J, Heine SJ, Norenzayan A (2010) The weirdest people in the world? Behav Brain Sci 33(2-3):61-83. https://doi. org/10.1017/S0140525X0999152X

29. Hoffmann F, Glaeske G, Bachmann CJ (2014) Trends in antidepressant prescriptions for children and adolescents in Germany from 2005 to 2012: antidepressants in German children and adolescents. Pharmacoepidemiol Drug Saf 23(12):1268-1272. https ://doi.org/10.1002/pds.3649

30. Holt-Lunstad J, Smith TB, Baker M, Harris T, Stephenson D (2015) Loneliness and social isolation as risk factors for mortality: a meta-analytic review. Perspect Psycholog Sci 10(2):227-237. https://doi.org/10.1177/1745691614568352

31. Jacobi F, Höfler M, Strehle J, Mack S, Gerschler A, Scholl L, Busch MA, Maske U, Hapke U, Gaebel W, Maier W, Wagner M, Zielasek J, Wittchen H-U (2014) Psychische Störungen in der Allgemeinbevölkerung: Studie zur Gesundheit Erwachsener in Deutschland und ihr Zusatzmodul Psychische Gesundheit (DEGS1-MH). Der Nervenarzt 85(1):77-87. https://doi. org/10.1007/s00115-013-3961-y

32. James SL, Abate D, Abate KH, Abay SM, Abbafati C, Abbasi N, Abbastabar H, Abd-Allah F, Abdela J, Abdelalim A, Abdollahpour I, Abdulkader RS, Abebe Z, Abera SF, Abil OZ, Abraha HN, AbuRaddad LJ, Abu-Rmeileh NME, Accrombessi MMK et al (2018) Global, regional, and national incidence, prevalence, and years lived with disability for 354 diseases and injuries for 195 countries and territories, 1990-2017: a systematic analysis for the Global Burden of Disease Study 2017. The Lancet 392(10159):17891858. https://doi.org/10.1016/S0140-6736(18)32279-7

33. Karim J, Weisz R, Bibi Z, Rehman S (2015) Validation of the eight-item center for epidemiologic studies depression scale (CES-D) among older adults. Curr Psychol 34(4):681-692. https ://doi.org/10.1007/s12144-014-9281-y

34. Kassebaum NJ, Arora M, Barber RM, Bhutta ZA, Brown J, Carter A, Casey DC, Charlson FJ, Coates MM, Coggeshall M, Cornaby L, Dandona L, Dicker DJ, Erskine HE, Ferrari AJ, Fitzmaurice C, Foreman K, Forouzanfar MH, Fullman N et al (2016) Global, regional, and national disability-adjusted life-years (DALYs) for 315 diseases and injuries and healthy life expectancy (HALE), 1990-2015: a systematic analysis for the Global Burden of Disease Study 2015. The Lancet 388(10053):1603-1658. https://doi. org/10.1016/S0140-6736(16)31460-X

35. Kendler KS (2016) The phenomenology of major depression and the representativeness and nature of DSM criteria. Am J Psychiatry 173(8):771-780. https://doi.org/10.1176/appi. ajp.2016.15121509

36. Keyes KM, Gary D, O'Malley PM, Hamilton A, Schulenberg J (2019) Recent increases in depressive symptoms among US adolescents: trends from 1991 to 2018. Soc Psychiatry Psychiatr Epidemiol 54(8):987-996. https://doi.org/10.1007/s00127-01901697-8

37. Kliem S, Beller J, Tibubos AN, Brähler E (2020) Normierung und Evaluation der Messinvarianz der 8-Item-Kurzform der Center of Epidemiological Studies-Depression Scale (CES-D8). Z Psychosom Med Psychother 66(3):259-271. https://doi. org/10.13109/zptm.2020.66.3.259

38. Kliem S, Beller J, Tibubos AN, Zenger M, Schmalbach B, Brähler E (2020) A reanalysis of the center for epidemiological studies depression scale (CES-D) using non-parametric item response theory. Psychiatry Res 290:113132. https://doi. org/10.1016/j.psychres.2020.113132

39. Kramer M (1980) The rising pandemic of mental disorders and associated chronic diseases and disabilities. Acta Psychiatr Scand 62(S285):382-397. https://doi. org/10.1111/j.1600-0447.1980.tb07714.x

40. Kröger C, Bode K, Wunsch E-M, Kliem S, Grocholewski A, Finger F (2015) Work-related treatment for major depressive disorder and incapacity to work: Preliminary findings of a controlled, matched study. J Occup Health Psychol 20(2):248-258. https://doi.org/10.1037/a0038341

41. Liu RT (2016) Taxometric evidence of a dimensional latent structure for depression in an epidemiological sample of 
children and adolescents. Psychol Med 46(6):1265-1275. https ://doi.org/10.1017/S0033291715002792

42. Lovibond PF (1998) Long-term stability of depression, anxiety, and stress syndromes. J Abnorm Psychol 107(3):520-526. https ://doi.org/10.1037/0021-843X.107.3.520

43. Ludwinek A, Sandor E, Clevers F (2019) Inequalities in the access of young people to information and support services.

44. Marsden PV, Wright JD (eds) (2010) Handbook of survey research, 2nd edn. Emerald, UK

45. Melkevik O, Clausen T, Pedersen J, Garde AH, Holtermann A, Rugulies R (2018) Comorbid symptoms of depression and musculoskeletal pain and risk of long term sickness absence. BMC Public Health 18(1):981. https://doi.org/10.1186/s12889-018-5740-y

46. Meyer JW, Ramirez FO, Soysal YN (1992) World expansion of mass education, 1870-1980. Sociol Educ 65(2):128. https://doi. org/10.2307/2112679

47. Mezuk B, Kendler KS (2012) Examining variation in depressive symptoms over the life course: a latent class analysis. Psychol Med 42(10):2037-2046. https://doi.org/10.1017/S003329171 200027X

48. Mojtabai R, Olfson M, Han B (2016) National trends in the prevalence and treatment of depression in adolescents and young adults. Pediatrics 138(6):e20161878-e20161878. https://doi.org/10.1542/ peds.2016-1878

49. Musliner KL, Munk-Olsen T, Eaton WW, Zandi PP (2016) Heterogeneity in long-term trajectories of depressive symptoms: patterns, predictors and outcomes. J Affect Disord 192:199-211. https://doi.org/10.1016/j.jad.2015.12.030

50. Stahmeyer J, Kuhlmann K, Eberhard S (2019) Die Häufigkeit von Depressionsdiagnosen nach Versichertengruppen im Zeitverlauf-eine Routinedatenanalyse der Jahre 2006-2015. PPmP Psychother Psych Med Psychol 69(02):72-80. https://doi. org/10.1055/a-0581-4785

51. Sullivan KJ, Liu A, Dodge HH, Andreescu C, Chang C-CH, Ganguli M (2020) Depression symptoms declining among older adults: birth cohort analyses from the Rust Belt. Am J
Geriatric Psychiatry 28(1):99-107. https://doi.org/10.1016/j. jagp.2019.06.002

52. Thorisdottir IE, Asgeirsdottir BB, Sigurvinsdottir R, Allegrante JP, Sigfusdottir ID (2017) The increase in symptoms of anxiety and depressed mood among Icelandic adolescents: time trend between 2006 and 2016. Eur J Pub Health 27(5):856-861. https ://doi.org/10.1093/eurpub/ckx111

53. Urbanos-Garrido RM, Lopez-Valcarcel BG (2015) The influence of the economic crisis on the association between unemployment and health: an empirical analysis for Spain. Eur J Health Econ 16(2):175-184. https://doi.org/10.1007/s10198-014-0563-y

54. Vigo D, Thornicroft G, Atun R (2016) Estimating the true global burden of mental illness. The Lancet Psychiatry 3(2):171-178. https://doi.org/10.1016/S2215-0366(15)00505-2

55. Vilagut G, Forero CG, Barbaglia G, Alonso J (2016) Screening for depression in the general population with the center for epidemiologic studies depression (CES-D): a systematic review with metaanalysis. PLoS ONE 11(5):e0155431. https://doi.org/10.1371/ journal.pone.0155431

56. Weinberger AH, Gbedemah M, Martinez AM, Nash D, Galea S, Goodwin RD (2018) Trends in depression prevalence in the USA from 2005 to 2015: widening disparities in vulnerable groups. Psychol Med 48(8):1308-1315. https://doi.org/10.1017/S0033 291717002781

57. Wiklund M, Malmgren-Olsson E-B, Öhman A, Bergström E, Fjellman-Wiklund A (2012) Subjective health complaints in older adolescents are related to perceived stress, anxiety and gender-a cross-sectional school study in Northern Sweden. BMC Public Health 12(1):993. https://doi.org/10.1186/1471-2458-12-993

58. Yang Y, Land K (2013) Age-period-cohort analysis: new models, methods, and empirical applications. Chapman and Hall/CRC. https://doi.org/10.1201/b13902

59. Zivin K, Pirraglia PA, McCammon RJ, Langa KM, Vijan S (2013) Trends in depressive symptom burden among older adults in the United States from 1998 to 2008. J Gen Intern Med 28(12):16111619. https://doi.org/10.1007/s11606-013-2533-y 